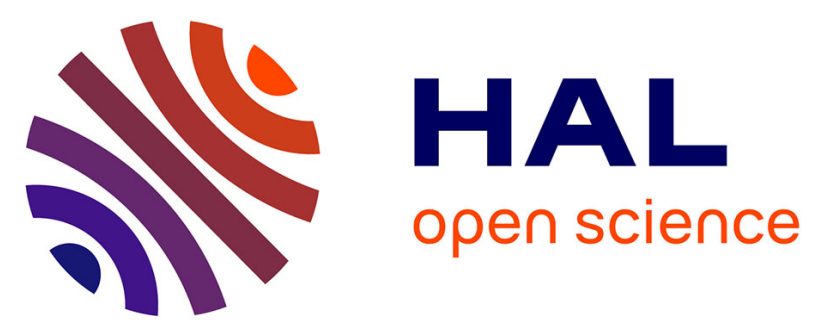

\title{
Estimating the impact of stroke unit care on stroke deaths in a whole population: An epidemiological study using routine data
}

Peter Langhorne, James Lewsey, Pardeep Jhund, Michelle Gillies, Jim Chalmers, Adam Redpath, Andrew Briggs, Matthew Walters, Simon

Capewell, John Mcmurray, et al.

\section{To cite this version:}

Peter Langhorne, James Lewsey, Pardeep Jhund, Michelle Gillies, Jim Chalmers, et al.. Estimating the impact of stroke unit care on stroke deaths in a whole population: An epidemiological study using routine data. Journal of Neurology, Neurosurgery and Psychiatry, 2010, 81 (12), pp.1301. 10.1136/jnnp.2009.195131 . hal-00557425

\section{HAL Id: hal-00557425 \\ https://hal.science/hal-00557425}

Submitted on 19 Jan 2011

HAL is a multi-disciplinary open access archive for the deposit and dissemination of scientific research documents, whether they are published or not. The documents may come from teaching and research institutions in France or abroad, or from public or private research centers.
L'archive ouverte pluridisciplinaire HAL, est destinée au dépôt et à la diffusion de documents scientifiques de niveau recherche, publiés ou non, émanant des établissements d'enseignement et de recherche français ou étrangers, des laboratoires publics ou privés. 
Estimating the impact of stroke unit care in a whole population:

An epidemiological study using routine data

Peter Langhorne ${ }^{1}$, James D Lewsey ${ }^{2}$, Pardeep S Jhund ${ }^{1}$, Michelle Gillies ${ }^{2}$, Jim W T Chalmers ${ }^{3}$, Adam Redpath ${ }^{3}$, Andrew Briggs ${ }^{2}$, Matthew Walters ${ }^{l}$, Simon Capewell ${ }^{4}$, John J V McMurray ${ }^{1}$, Kate MacIntyre ${ }^{2}$.

1. Cardiovascular and Medical Sciences Division, University of Glasgow, Glasgow, UK

2. Section of Public Health and Health Policy, University of Glasgow, Glasgow $U K$

3. Information Services Division, Edinburgh, $U K$

4. Department of Public Health, University of Liverpool, Liverpool UK

Corresponding author:

Peter Langhorne

Professor of Stroke Care

Academic Section of Geriatric Medicine

Level 3 University Block

Royal Infirmary

Glasgow. G31 2ER

Tel: 01412114976

Fax: 01412114033

Email: P.Langhorne@clinmed.gla.ac.uk

Word count: 2148 


\begin{abstract}
Background and Purpose: Randomised trials indicate that organised inpatient (stroke unit) care has an important impact on patient outcomes with an absolute risk difference $(A R D)$ of $3 \%$ for survival and 5\% for returning home. However, it is unclear what impact this complex intervention actually has in routine practice. We used a comprehensive National dataset to study the impact of stroke unit implementation.
\end{abstract}

Methods: We used the Scottish linked discharge database to identify all patients admitted to hospital with an incident stroke. Analyses compared case fatality and discharge home (adjusted for age, sex, deprivation and co-morbidity) for hospitals with or without a stroke unit during four consecutive study periods (1986-90, 199195, 1996-2000, 2001-05).

Results: During the study period the percentage of admissions to hospitals that had a stroke unit rose from $0 \%$ to $87 \%$, the six-month case fatality dropped from $45 \%$ to $29 \%$ and discharges home rose from $46 \%$ to $59 \%$. Adjusted odds ratios (95\% CI) for case fatality (stroke unit versus no unit) in each study period were; not calculable (no units before 1991), 0.83 (0.78-0.89), 0.90 (0.86-0.94), 0.87 (0.82-0.91). These equate to an ARD of $3.0 \%$ over the whole study period. Equivalent data for discharge home indicated an increased odds of discharge home; not calculable, 1.23 (1.15-1.31), 1.15 (1.10-1.21), 1.17 (1.11-1.23) with an overall ARD of 5\%. 
Conclusions: These results indicate a positive impact of a policy of stroke unit care on case fatality and discharge home. The estimated impact, after adjusting for case mix, appears very similar to that calculated using clinical trial data. 


\section{INTRODUCTION}

Organised inpatient (stroke unit) care has been shown to be effective in randomised trials. Patients who are managed within a stroke unit are more likely to survive, return home and regain independence.[1] However, organised stroke unit care is a complex intervention with many facets that are difficult to define and replicate.[2] This raises challenges and uncertainties when implementing into routine services. Also, randomised trials are often carried out under unusual controlled conditions and may not be easily reproduced in routine practice. Some of these potential concerns about implementing stroke unit care were addressed by a systematic review of observational studies which suggested that stroke units may have a similar effect on case fatality when applied in more routine care settings.[3] However this review identified a number of study limitations including incomplete casemix adjustment, limited definition of service characteristics, possible selective admission to stroke units and short study periods.

Therefore important uncertainties remain about several issues. Firstly, does the benefit of stroke unit care extend across a broad range of stroke patients, in particular those with poorer prognosis who make the biggest contribution to stroke-related death and disability? Secondly, there might be the selective admission of patients to stroke units that produces a biased (favourable) estimate of benefit. Casemix adjustment may not completely compensate for this bias. Finally, most studies have used a rather informal, self-defined description of stroke unit care, which has not been externally validated. 
This current study arose from the unique opportunities within Scotland to use comprehensive, linked hospital discharge data (collected over a 20-year period), to study the association between well characterised hospital services outcome (case fatality and discharge home) of stroke patients. The study allowed us to explore changes in outcome during the period in which stroke units moved from being nonexistent (prior to 1990) to being recommended in clinical practice guidelines (in 1995),[4] and finally being established within the government health strategy (in 2002).[5] 


\section{METHODS}

Scotland has a population of 5.1 million and an estimated annual number of strokes in excess of 10,000 per annum of whom the majority are admitted to hospital [5].

The Information Services Division (ISD) of the National Health Service (NHS) in Scotland collects data on all discharges in NHS hospitals using the Scottish Morbidity Record (SMR) Scheme. Data from patient case records are used to code up to six diagnoses at the time of discharge according to the World Health Organisation Classification of Diseases (ICD 9 prior to 1996, ICD 10, after 1996). The term "discharge" includes both live discharges and deaths. These data routinely link to information held by the General Register Office for Scotland that records information relating to all deaths in Scotland, including those that occur in individuals not previously hospitalised.

We identified all hospitalisations in Scotland for the period 1981-2005 where stroke was coded as the principal (first position) diagnosis at discharge. The following ICD9 and ICD10 codes were used to identify stroke (ICD10 codes are underlined): 430 (subarachnoid haemorrhage), 431 (intracerebral haemorrhage), 433 (occlusion and stenosis of precerebral arteries), 434 (occlusion of cerebral arteries), 436 (acute, but

ill-defined cerebrovascular disease), $\underline{\text { I60 }}$ (subarachnoid haemorrhage), $\underline{\text { 661 }}$ (intracerebral haemorrhage), $\underline{\text { I } 63}$ cerebral infarction), $\underline{\text { I } 44}$ (stroke, not specified as haemorrhage or infarction). Further detail on how incident stroke was defined is described elsewhere.[6] SMR identifies stroke with an accuracy of 95\% when the stroke code is recorded in the principle diagnostic position (ISD Data Quality 
Assurance). A number of comorbidities were identified and recorded as in previous publications.[6] These included principal and secondary diagnoses for any previous hospitalisations in the last 5 years and secondary diagnoses recorded in the incident stroke hospitalisation: diabetes, cancer, respiratory disease, heart failure, peripheral arterial disease, atrial fibrillation essential hypertension, renal failure, coronary artery disease, valvular heart disease, venous thrombolembolism, obstructive sleep apnoea, depression, Parkinsonism, dementia, falls and fractures, and alcohol misuse.

A standard definition of stroke unit was used; an area within a hospital where stroke patients are managed by a co-ordinated multidisciplinary team specialising in stroke management.[1-2] The multi-disciplinary team would meet at least once per week to plan patient care. Our broad definition of stroke unit did not discriminate between those providing acute care only, rehabilitation care only or a combination of the two (comprehensive unit). However the majority of units studied (17/19) were comprehensive or rehabilitation units. We identified the development of stroke unit care at two levels; a) the time when a hospital had any form of stroke unit service and b) the time when a hospital had a stroke unit service that had the capacity to manage at least $50 \%$ of its stroke patient admissions. The existence and capacity of stroke units was identified through a range of approaches including:

1) Audits of stroke services carried out at intervals over the last 15 years,[7]

2) Informal surveys carried out over the last 15 years to inform healthcare policy,[5]

3) A national survey and quality assurance inspection of Stroke Services,[8]

4) The National Scottish Stroke Care Audit; operating during the last 9 years,[9] 
5) Personal contact through a national network of stroke clinicians (Scottish Stroke Collaboration).

A number of approaches were taken in the analysis of outcomes. Firstly we analysed the basic descriptive statistics of the number of stroke patients admitted to hospital over a 20-year period, the number of hospitals which had a stroke unit service and hence the number of stroke patients admitted to a hospital that could provide such a service. Secondly, we analysed 6 month case fatality and discharge destination outcomes, comparing hospitals with and without a stroke unit, and stratifying the analysis by the period of time (1986-90, 1991-95, 1996-2000, 2001-05). We compared outcomes in (a) a hospital without a stroke unit compared to one with a stroke unit, and (b) a hospital with a 'functional' stroke unit that could manage at least $50 \%$ of its stroke patient population versus one which could not manage $50 \%$ of its stroke patients. These analyses looked at crude outcomes plus the odds ratio for outcomes in a hospital with a stroke unit service. The odd ratios were calculated both for crude data and those adjusted for age, sex, socioeconomic deprivation (defined using the Carstairs-Morris index of deprivation) and comorbidity. In addition, the absolute risk reduction (ARR) was calculated using odds ratios (ORs) and case fatality $(\mathrm{CF})$ without stroke unit care as follows:[10]

$$
(1-\mathrm{CF} \times \mathrm{CF} \times(1-\mathrm{OR}))
$$

$$
1-(\mathrm{CF} \times(1-\mathrm{OR})) \text {. }
$$

The same approach was used for discharge outcome where the CF variable was the proportion discharged home from hospitals without stroke unit care. 


\section{RESULTS}

\section{Study Population}

From $1^{\text {st }}$ January 1986 to $31^{\text {st }}$ December 2005 there were 157,639 incident strokes recorded in Scotland and 55\% were in women. The median age was 74 years (IQR 65 - 82). It can be seen from Table 1 that the distribution of age and sex were invariant over time and the socioeconomic gradient was less pronounced towards the end of the study period. The prevalence of most comorbidities increased over time.

Figure 1 shows the 6-month case fatality over the 20 -year period. Also shown is the proportion of hospitals with a stroke unit service of any kind or a 'functional' service able to provide for at least $50 \%$ of stroke patient admissions. There was a steady fall in case fatality over the study period. From the mid-1990s, there was a rapid rise in the proportion of hospitals with stroke unit services.

Table 2 shows the demographics of stroke patients treated in a hospital where there was a stroke unit compared to stroke patients treated in a hospital with no stroke unit. Patients treated in a hospital with a stroke unit were younger on average, had a higher percentage of people from the most deprived socioeconomic deprivation fifth, and had higher prevalence of comorbidites especially atrial fibrillation, essential hypertension, coronary heart disease and alcohol misuse. 
Table $3 a$ shows the 6-month case fatality in hospitals with and without a stroke unit and when comparing a hospital with a stroke service able to provide for $50 \%$ of patients versus hospitals without such a service. Crude case fatality rates in hospitals with a stroke unit were consistently lower than in hospitals without a stroke unit.

Table $3 b$ shows the same analysis for discharge home which was consistently higher in hospitals with a stroke unit.

Table $4 a$ shows the adjusted and unadjusted odds ratios for 6-month case fatality in hospitals, with and without a stroke unit, stratified by study period. Also shown is the comparison of hospitals able to provide stroke unit care for at least $50 \%$ of their stroke patients versus those that could not. The apparent odds reduction for death in patients admitted to a hospital with a stroke unit was consistently $17-23 \%$ compared with hospitals without a stroke unit. The apparent odds reduction for death (22\%-38\%) was more marked when using this stricter definition of a 'functional' stroke unit service that could take at least $50 \%$ of stroke patients. In both examples, the odds reductions for death were attenuated but not abolished after casemix adjustment.

Table $4 b$ shows the same analysis for the outcome discharge home. There was an increase in the odds of discharge home associated with stroke unit hospitals. This increase was $17-23 \%$ after casemix adjustment.

Table $5 a$ compares estimated the impact of a stroke unit policy on 6-month case fatality using three different approaches; a) the crude data observed in this analysis (estimated 2440 additional survivors), b) an estimate calculated using the adjusted 
odds ratios (Table 4) from this analysis (estimated 1420 additional survivors) and, c) an estimate calculated from the 3\% ARR seen in randomised trials, (estimated 1425 additional survivors). The increasing access to stroke units in Scotland was associated with a substantial increase in survivors. During the period of stroke unit development (1991-2005) 6-month case fatality fell from $41 \%$ to $29 \%$ (i.e. ARR of $12 \%$ ). The estimate that is stratified by time period and adjusted for casemix suggests that an ARR of $2-4 \%$ may be attributed to the impact of stroke unit care. In the final study period (2001-05) when stroke units were most prevalent stroke unit care appeared to account for almost 200 extra survivors per year.

Table $5 b$ shows the same analysis but using discharge home as the variable in place of case fatality. During the period of stroke unit development (1991-2005) the proportion discharge home rose from $43 \%$ to $61 \%$ (i.e. an absolute increase of $18 \%$ ) of which 4-6\% might be attributed to the impact of stroke unit care. In the final study period (2001-2005) an extra 470 discharges per year could be attributed to stroke unit care.

\section{DISCUSSION}

Stroke case fatality recorded using routine data has fallen substantially during this 20year national study. It is apparent from this analysis that the development of stroke units could partly explain the fall in case fatality in hospitalised stroke patients. The remaining component may be explained by artefact (more stroke patients admitted to hospital with milder symptoms),[11-12] changes in the natural history of stroke (e.g. less severe stroke events)[11-12] and improvements in general medical care.[12] 
We believe this is the first long-term study to have shown such an association in a whole population. The potential impact when based on unadjusted data, is even larger than would have been estimated from randomised trials of stroke unit care. However unadjusted estimates may be confounded by variations in casemix such as patient age and stroke severity. The estimate based on analyses adjusted for casemix (1420 extra survivors and 2351 extra discharges home) was very similar to that obtained using the absolute risk reductions from meta-analysis of clinical trials. Although no single method of estimating impact is ideal it is reassuring to obtain similar estimates from different approaches.

The main strengths of our study are that we have studied a whole population of 5.1 million people over a 20 -year period with complete follow-up to one-year post stroke. Secondly, we used a definition of stroke unit status that has a standard definition and was externally validated.[5,7,8,9]. The basic definition (2) was of multidisciplinary stroke unit care and the majority were comprehensive (acute and rehabilitation) or rehabilitation stroke units (5). Finally, our focus on whole hospital services minimises the risk of bias in patient selection for admission to a stroke unit since most hospitals served all patients within a geographical area. Alternative explanations of our observations (e.g. hospitals with better case fatality results were more likely to establish stroke units) do not seem plausible.

The mechanisms by which stroke units improve survival has been subject to some study. In randomised trials, the survival benefit occurs largely at 1-4 weeks post stroke,[13] is more marked in severe stroke patients,[13] and is linked to a reduction 
in complications, particularly those caused by immobility.[14] The scale of benefit observed in our study is compatible with these observations. Furthermore, the size of association is also similar to that seen in a recent population-based observational study from Sweden [adjusted HR (stroke unit vs. no stroke unit) for death equal to 0.79 in men and 0.83 in women].[15] Our results cannot be explained by hyperacute interventions such as thrombolysis which were not in routine use during the period of study, would not be expected to reduce case fatality,[16] and would have a modest impact at a population level.[17]

There are some limitations to our study. Firstly, we used hospital discharge data and we therefore cannot always be certain of the precision of the diagnoses. However, audit carried out by Information Services Division suggest that SMR identified stroke with an accuracy of $95 \%$ when a stroke code is recorded in the first diagnostic position.[18] Secondly, although we included the key variables of age, sex, deprivation and co-morbidity, our risk adjustments will not be complete because of lack of clinical detail on items such as stroke severity. Finally, we were not able to directly study non-fatal outcomes such as disability. However, data from randomised trials [1] indicate that the benefits in survival are mirrored by improvements in functional recovery and that discharge home is a reasonable proxy for functional recovery.

\section{CONCLUSIONS}

Stroke case fatality in Scotland has fallen steadily and substantially over two decades and has been mirrored by a rise in discharges home. Part of this improvement in 
prognosis can be explained by the policy of implementing a basic model of multidisciplinary stroke unit care.

\section{Acknowledgements:}

This study was funded by the Chief Scientist Office (CSO) grant number CZH/4/389.

We are grateful to all the stroke clinicians who provided information about stroke services in Scotland.

\section{Licence for Publication:}

The Corresponding Author has the right to grant on behalf of all authors and does grant on behalf of all authors, an exclusive licence (or non exclusive for government employees) on a worldwide basis to the BMJ Publishing Group Ltd to permit this article (if accepted) to be published in PMJ and any other BMJPGL products and sublicences such use and exploit all subsidiary rights, as set out in our licence. 


\section{REFERENCES}

1) Stroke Unit Trialists' collaboration. Organised inpatient (stroke unit) care for stroke. Cochrane Database System Rev. 2007;4:CD000197.

2) Langhorne P, Dennis MS. Stroke units: an evidence-based approach. BMJ Publishing, London 1998.

3) Seenan P, Long M, Langhorne P. Stroke units in their natural habitat: a systematic review of observational studies. Stroke 2007;38:1886-92.

4) Scottish Intercollegiate Guidelines Network (SIGN) Guideline No. 13. Management of patients with stroke part I: Assessment, investigation, immediate management and secondary prevention. July 1995. www.sign.ac.uk

5) Coronary Heart Disease and Stroke: Strategy for Scotland. Scottish Government Publications, October 2002.

6) Lewsey JD, Gillies M, Jhund PS, et al. Sex Differences in Incidence, Mortality, and Survival in Individuals With Stroke in Scotland, 1986 to 2005. Stroke 2009;40:1038-1043.

7) Dennis M, Flaig R, McDowall M. Scottish Stroke Care Audit. Stroke services in Scottish Hospitals 2008 National Report Information Services Division, Scotland 2008.

8) Scottish Stroke Services Audit (1999). www.show.scot.nhs.uk/crag

9) National Report on Stroke Services in Scottish Hospitals in 2005/06. The Scottish Stroke Care Audit. NHS QIS 2006.

10) Sackett DL, Richardson WS, Rosenberg W, et al. Evidence-based medicine : how to practice and teach EBM. Churchill Livingstone, 1997. 
11) Rothwell PM, Coull AJ, Giles MF, et al. Change in stroke incidence, mortality, case-fatality, severity, and risk factors in Oxfordshire, UK from 1981 to 2004 (Oxford Vascular Study). Lancet. 2004;363:1925-1933.

12) Warlow C, van Gijn J, Dennis M, et al. Stroke: practical management. $3^{\text {rd }}$ edition. Blackwell Publishing 2008.

13) Stroke Unit Trialists' Collaboration. Collaborative systematic review of the randomised trials of organised inpatient (stroke unit) care after stroke. BMJ $1997 ; 314: 1151-9$

14) Govan L, Langhorne P, Weir C for the Stroke Unit Trialists Collaboration. Does the prevention of complications explain the survival benefit of organised inpatient (stroke unit) care? Further analysis of a systematic review. Stroke 2007;38:2536-40.

15) Terént A, Asplund K, Farahmand B, et al. Stroke unit care revisitied: who benefits the most? A cohort study of 105043 patients in Riks-Stroke, the Swedish Stroke Register. Journal of Neurology, Neurosurgery and Psychiatry 2009;80:881-887.

16) Wardlaw JM, del Zoppo GJ, Yamaguchi T, et al. Thrombolysis for acute ischaemic stroke. Cochrane Database of Systematic Reviews 2003, Issue 3. Art. No.: CD000213. DOI: 10.1002/14651858.CD000213.

17) Gilligan AK, Thrift AG, Sturm JW, et al. Stroke units, tissue plasminogen activator, aspirin and neuroprotection. Which stroke intervention provides the greatest community benefit? Cerebrovasc Dis 2005;20:239-244.

18) ISD Data Quality Assurance. Towards Better Data from Scottish Hospitals: An Assessment of SMR01 and Associated Data 2004 - 2006. 
http://www.isdscotland.org/isd/files/SMR01\%20Scotland\%20Report\%202007

.pdf . 2007. 
Table 1 Demographics of incident strokes 1986 - 1990

\begin{tabular}{|c|c|c|c|c|c|}
\hline Demographic & $\begin{array}{l}\text { 1986- } \\
\mathbf{1 9 9 0} \\
\mathrm{n}=38,622\end{array}$ & $\begin{array}{l}\text { 1991- } \\
\mathbf{1 9 9 5} \\
\mathrm{n}=41,769 \\
\end{array}$ & $\begin{array}{l}\text { 1996- } \\
\mathbf{2 0 0 0} \\
n=40,146\end{array}$ & $\begin{array}{l}\text { 2001- } \\
\mathbf{2 0 0 5} \\
n=37,102\end{array}$ & $\begin{array}{l}\text { Overall } \\
n=157,639\end{array}$ \\
\hline $\begin{array}{l}\text { Age (years) - } \\
\text { median (IQR) }\end{array}$ & $74(65-81)$ & $74(65-82)$ & $74(64-82)$ & $74(64-82)$ & $74(65-82)$ \\
\hline $\begin{array}{l}\text { Sex -\% women } \\
\text { Socioeconomic } \\
\text { deprivation }-\%\end{array}$ & 56.6 & 55.7 & 54.1 & 54.1 & 55.1 \\
\hline 1 (least dep.) & 16.7 & 16.4 & 17.6 & 18.2 & 17.2 \\
\hline 2 & 19.8 & 19.8 & 20.0 & 20.3 & 20.0 \\
\hline 3 & 18.1 & 19.1 & 19.5 & 19.6 & 19.1 \\
\hline 4 & 21.2 & 21.3 & 20.9 & 20.3 & 20.9 \\
\hline $\begin{array}{l}5 \text { (most dep.) } \\
\text { Comorbidities -\% }\end{array}$ & 24.2 & 23.4 & 22.0 & 21.6 & 22.8 \\
\hline Diabetes & 6.4 & 7.9 & 10.0 & 12.0 & 9.0 \\
\hline Cancer & 4.6 & 5.8 & 7.6 & 8.1 & 6.5 \\
\hline Respiratory disease & 4.5 & 5.9 & 7.8 & 9.3 & 6.9 \\
\hline Heart failure & 6.7 & 8.0 & 8.2 & 7.8 & 7.7 \\
\hline $\begin{array}{l}\text { Peripheral arterial } \\
\text { disease }\end{array}$ & 5.7 & 6.4 & 6.6 & 6.2 & 6.2 \\
\hline $\begin{array}{l}\text { Atrial fibrillation } \\
\text { Essential }\end{array}$ & 6.1 & 9.0 & 13.3 & 17.1 & 11.3 \\
\hline hypertension & 9.0 & 12.7 & 20.9 & 34.7 & 19.1 \\
\hline Renal failure & 1.3 & 1.9 & 2.9 & 4.3 & 2.6 \\
\hline $\begin{array}{l}\text { Coronary heart } \\
\text { disease }\end{array}$ & 13.3 & 16.5 & 19.1 & 21.5 & 17.6 \\
\hline $\begin{array}{l}\text { Rheumatic/valvular } \\
\text { heart disease }\end{array}$ & 1.5 & 2.0 & 2.7 & 3.6 & 2.4 \\
\hline $\begin{array}{l}\text { Pulmonary } \\
\text { embolism \& DVT }\end{array}$ & 1.7 & 1.9 & 2.5 & 2.5 & 2.1 \\
\hline Depression & 1.0 & 1.6 & 2.0 & 2.6 & 1.8 \\
\hline Parkinsonism & 1.4 & 1.3 & 1.1 & 1.1 & 1.2 \\
\hline Dementia & 3.0 & 3.5 & 4.3 & 4.9 & 3.9 \\
\hline Falls \& Fracture & 7.7 & 8.5 & 9.2 & 9.9 & 8.8 \\
\hline Alcohol misuse & 1.8 & 2.8 & 4.0 & 5.2 & 3.5 \\
\hline
\end{tabular}


Table 2 Demographics of incident strokes by whether there was a stroke unit in hospital or not

\begin{tabular}{|c|c|c|}
\hline Demographic & $\begin{array}{l}\text { No stroke unit in hospital } \\
\mathrm{n}=110,207\end{array}$ & $\begin{array}{l}\text { Stroke unit } \\
\mathrm{n}=47,432\end{array}$ \\
\hline $\begin{array}{l}\text { Age (years) - } \\
\text { median (IQR) }\end{array}$ & $75(66-82)$ & $73(63-81)$ \\
\hline $\begin{array}{l}\text { Sex }-\% \text { women } \\
\text { Socioeconomic } \\
\text { deprivation }-\%\end{array}$ & 55.6 & 54.0 \\
\hline 1 (least dep.) & 16.2 & 19.5 \\
\hline 2 & 21.9 & 15.7 \\
\hline 3 & 19.8 & 17.4 \\
\hline 4 & 21.2 & 20.2 \\
\hline $\begin{array}{l}5 \text { (most dep.) } \\
\text { Comorbidities }-\%\end{array}$ & 20.9 & 27.2 \\
\hline Diabetes & 8.3 & 10.8 \\
\hline Cancer & 6.0 & 7.7 \\
\hline Respiratory disease & 6.1 & 8.6 \\
\hline Heart failure & 7.7 & 7.7 \\
\hline $\begin{array}{l}\text { Peripheral arterial } \\
\text { disease }\end{array}$ & 6.2 & 6.3 \\
\hline $\begin{array}{l}\text { Atrial fibrillation } \\
\text { Essential }\end{array}$ & 9.5 & 15.4 \\
\hline hypertension & 14.5 & 29.8 \\
\hline Renal failure & 2.2 & 3.5 \\
\hline $\begin{array}{l}\text { Coronary heart } \\
\text { disease }\end{array}$ & 16.2 & 20.6 \\
\hline $\begin{array}{l}\text { Rheumatic/valvular } \\
\text { heart disease }\end{array}$ & 2.1 & 3.2 \\
\hline $\begin{array}{l}\text { Pulmonary } \\
\text { embolism \& DVT }\end{array}$ & 2.1 & 2.3 \\
\hline Depression & 1.6 & 2.2 \\
\hline Parkinsonism & 1.3 & 0.9 \\
\hline Dementia & 3.7 & 4.3 \\
\hline Falls \& Fracture & 8.7 & 9.0 \\
\hline Alcohol misuse & 2.8 & 4.9 \\
\hline
\end{tabular}


Table 3 Crude outcomes (with $95 \%$ CI) by stroke unit status and study period; a) 6 month case fatality, b) proportion (\%) discharged home

a) Case fatality

\begin{tabular}{lll}
\hline Study period & No stroke unit in hospital & Stroke unit \\
\hline $1986-1990$ & $42.8(42.3,43.3)$ & \\
$1991-1995$ & $39.8(39.3,40.3)$ & $34.1(32.7,35.4)$ \\
$1996-2000$ & $35.9(35.3,36.5)$ & $31.7(31.0,32.4)$ \\
$2001-2005$ & $34.6(33.7,35.6)$ & $29.0(28.4,29.5)$ \\
& & \\
Study period & Stroke unit care available for & Stroke unit care available \\
& $\leq \mathbf{5 0 \%}$ & for $>\mathbf{5 0 \%}$ \\
$1986-1990$ & $47.7(47.2,48.2)$ & \\
$1991-1995$ & $44.6(44.1,45.1)$ & $33.1(31.4,34.9)$ \\
$1996-2000$ & $40.1(39.6,40.7)$ & $32.5(31.5,33.5)$ \\
$2001-2005$ & $37.4(36.8,38.1)$ & $31.8(31.1,32.5)$ \\
& & \\
\hline
\end{tabular}

b) Discharge home

\begin{tabular}{lll}
\hline Study period & No stroke unit in hospital & Stroke unit \\
\hline & & \\
$1986-1990$ & $46.4(45.9,46.9)$ & $57.0(55.6,58.5)$ \\
$1991-1995$ & $50.6(50.0,51.1)$ & $59.9(59.1,60.6)$ \\
$1996-2000$ & $53.6(53.0,54.3)$ & $63.2(62.6,63.8)$ \\
$2001-2005$ & $56.0(55.0,57.0)$ & \\
& & Stroke unit care available \\
ftudy period & Stroke unit care available & \\
& for $\leq \mathbf{5 0 \%}$ & \\
$1986-1990$ & $46.4(45.9,46.9)$ & $62.5(60.6,64.3)$ \\
$1991-1995$ & $50.5(50.0,51.0)$ & $62.8(61.8,63.9)$ \\
$1996-2000$ & $54.3(53.8,54.9)$ & $64.6(63.9,65.3)$ \\
$2001-2005$ & $58.4(57.7,59.1)$ & \\
& & \\
\hline
\end{tabular}


Table 4 Crude and adjusted odds ratios (stroke unit in hospital $v s$. no stroke unit in hospital); a) 6-month case fatality b) proportion (\%) discharged home

a) Case fatality

\begin{tabular}{|c|c|c|}
\hline $\begin{array}{l}\text { Stroke unit in hospital } \\
\text { Period }\end{array}$ & Crude OR & Adjusted OR* \\
\hline $1991-1995$ & $0.78(0.73,0.83)$ & $0.83(0.78,0.89)$ \\
\hline $1996-2000$ & $0.83(0.79,0.86)$ & $0.90(0.86,0.94)$ \\
\hline $2001-2005$ & $0.77(0.73,0.81)$ & $0.87(0.82,0.91)$ \\
\hline \multicolumn{3}{|c|}{ Stroke unit care available for $>50 \%$ of admissions } \\
\hline Period & Crude OR & Adjusted OR* \\
\hline $1991-1995$ & $0.62(0.57,0.67)$ & $0.73(0.67,0.80)$ \\
\hline $1996-2000$ & $0.73(0.69,0.77)$ & $0.85(0.80,0.90)$ \\
\hline $2001-2005$ & $0.78(0.75,0.82)$ & $0.85(0.81,0.89)$ \\
\hline
\end{tabular}

b) Discharge home

\begin{tabular}{lcc}
\hline $\begin{array}{l}\text { Stroke unit in hospital } \\
\text { Period }\end{array}$ & Crude OR & Adjusted OR* \\
\hline & $1.30(1.22,1.38)$ & $1.23(1.15,1.31)$ \\
$1991-1995$ & $1.29(1.24,1.34)$ & $1.15(1.10,1.21)$ \\
$1996-2000$ & $1.35(1.29,1.41)$ & $1.17(1.11,1.23)$ \\
$2001-2005$ & & \\
Stroke unit care available for $>\mathbf{5 0 \%}$ of admissions & Adjusted OR* \\
Period & Crude OR & $1.35(1.23,1.47)$ \\
& $1.63(1.51,1.77)$ & $1.20(1.13,1.26)$ \\
$1991-1995$ & $1.42(1.35,1.49)$ & $1.15(1.10,1.20)$ \\
$1996-2000$ & $1.30(1.24,1.35)$ & \\
$2001-2005$ & & \\
& $*$ adjusted for age, sex, socioeconomic deprivation and comorbidity
\end{tabular}


Table 5 Calculated impact of stroke unit care in Scotland, 1986 - 2005

a) Case fatality

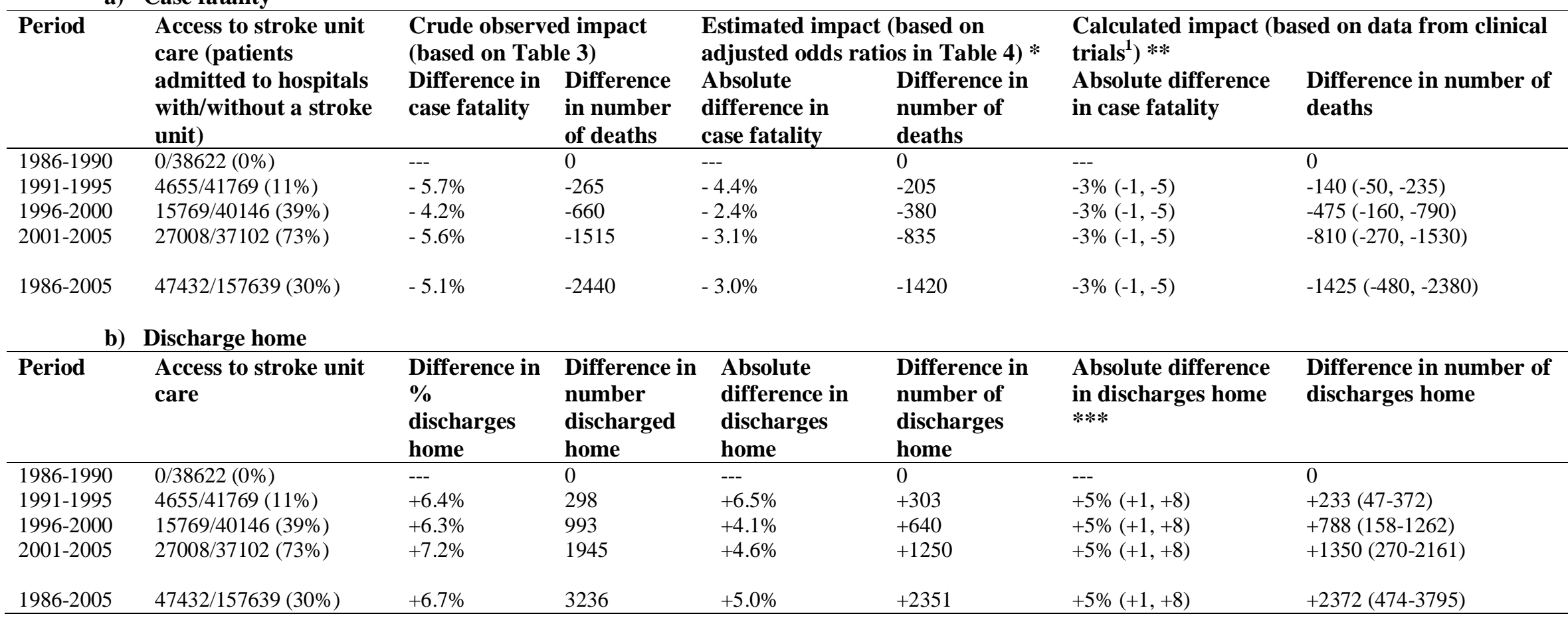

* The absolute risk reduction (10) was calculated from odds ratios (ORs) as;

$(1-\mathrm{CF} \times \mathrm{CF} \times(1-\mathrm{OR})$

$1-[\mathrm{CF} \times(1-\mathrm{OR})]$

where $\mathrm{CF}$ is; a) case fatality without stroke unit care, or b) proportion discharged home without stroke unit care

** Calculated using the absolute risk difference (95\% confidence interval) for case fatality from clinical trials of stroke unit care. $* * *$ Based on absolute risk difference (95\% confidence interval) for the proportion living at home in clinical trials 
Figure 1: 6-month case fatality, percentage of hospitals with any stroke unit, percentage of hospitals with stroke unit able to provide for at least $50 \%$ of stroke patients, plotted against study year

\section{Legend}

Solid line, triangle marker - 6-month case fatality.

Dashed line, triangle marker - $\%$ of hospitals with stroke unit providing for $50 \%$.

Dashed line, circle marker - \% of hospitals with stroke unit. 


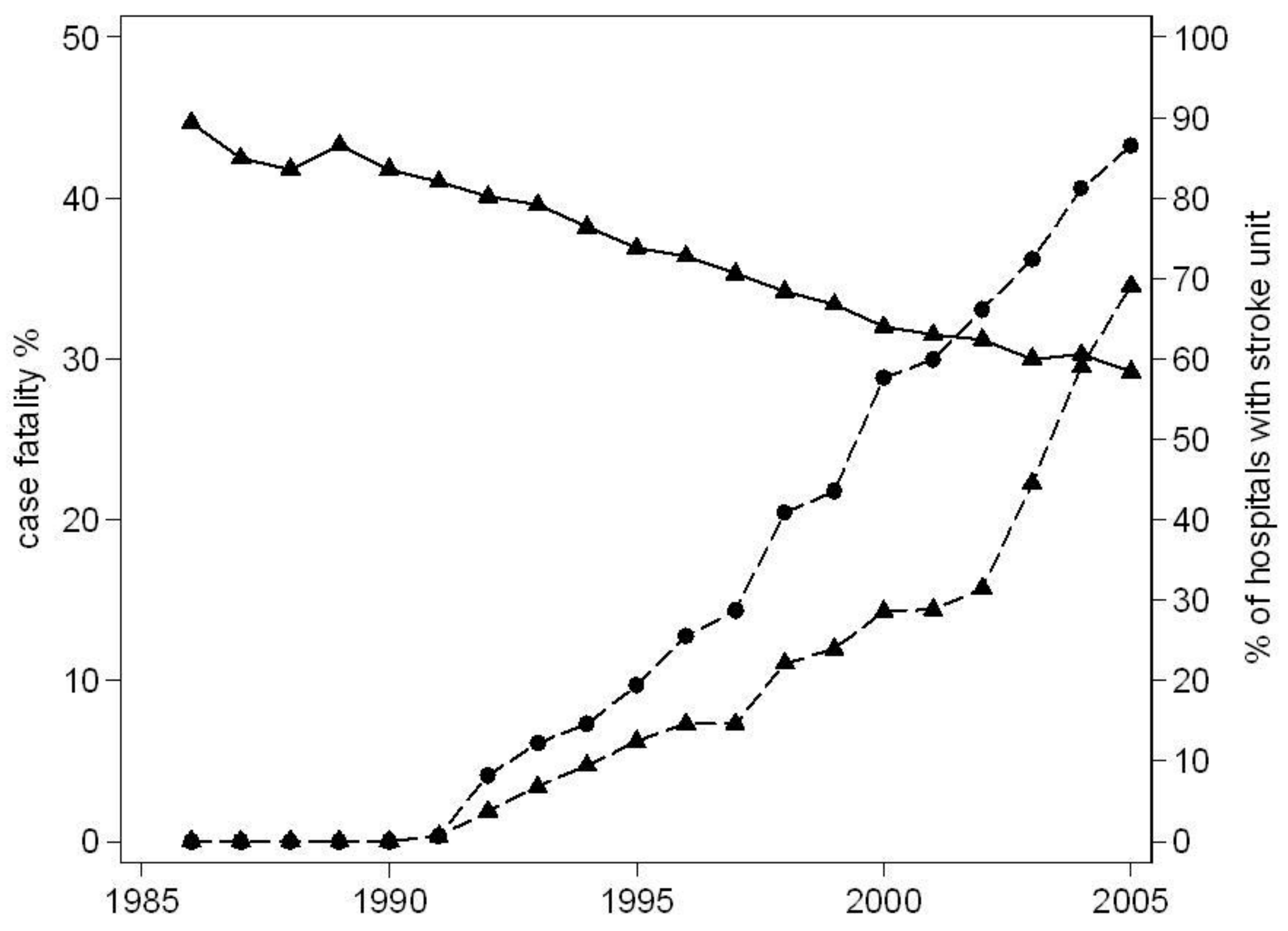

